\title{
RESEARCH
}

Open Access

\section{Up-regulation of microglial cathepsin C expression and activity in lipopolysaccharide -induced neuroinflammation}

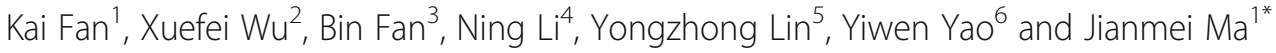

\begin{abstract}
Background: Cathepsin C (Cat C) functions as a central coordinator for activation of many serine proteases in inflammatory cells. It has been recognized that $C a t C$ is responsible for neutrophil recruitment and production of chemokines and cytokines in many inflammatory diseases. However, Cat C expression and its functional role in the brain under normal conditions or in neuroinflammatory processes remain unclear. Our previous study showed that Cat $C$ promoted the progress of brain demyelination in cuprizone-treated mice. The present study further investigated the Cat C expression and activity in lipopolysaccharide (LPS)-induced neuroinflammation in vivo and in vitro.

Methods: C57BL/6 J mice were intraperitoneally injected with either $0.9 \%$ saline or lipopolysaccharide (LPS, $5 \mathrm{mg}$ / $\mathrm{kg})$. Immunohistochemistry (IHC) and in situ hybridization (ISH) were used to analyze microglial activation, TNF-a, IL$1 \beta, I L-6$, iNOS mRNAs expressions and cellular localization of Cat $C$ in the brain. Nitrite assay was used to examine microglial activation in vitro; RT-PCR and ELISA were used to determine the expression and release of Cat C. Cat C activity was analyzed by cellular Cat $C$ assay kit. Data were evaluated for statistical significance with paired $t$ test.

Results: Cat C was predominantly expressed in hippocampal CA2 neurons in C57BL/6 J mice under normal conditions. Six hours after LPS injection, Cat C expression was detected in cerebral cortical neurons; whereas, twenty-four hours later, Cat $C$ expression was captured in activated microglial cells throughout the entire brain. The duration of induced Cat $C$ expression in neurons and in microglial cells was ten days and three days, respectively. In vitro, LPS, IL-1 $\beta$ and IL-6 treatments increased microglial Cat C expression in a dose-dependent manner and upregulated $C a t C$ secretion and its activity.
\end{abstract}

Conclusions: Taken together, these data indicate that LPS and proinflammatory cytokines IL-1ß, IL-6 induce the expression, release and upregulate enzymatic activity of Cat $C$ in microglial cells. Further investigation is required to determine the functional role of $\mathrm{Cat} C$ in the progression of neuroinflammation, which may have implications for therapeutics for the prevention of neuroinflammation-involved neurological disorders in the future.

Keywords: Cathepsin C, Microglia, Lipopolysaccharide, Neuroinflammation

\footnotetext{
* Correspondence: ma_jianmei@hotmail.com

${ }^{1}$ Department of Anatomy, Dalian Medical University, No. 9, West Segment of South Lvshun Road, Dalian, Liaoning 116044, China

Full list of author information is available at the end of the article
} 


\section{Background}

Neuroinflammation is associated with many neurodegenerative diseases, including Alzheimer's disease, Parkinson's disease, amyotrophic lateral sclerosis, and multiple sclerosis. The ubiquitous pathological changes of neuroinflammation in these diseases include overactivation of glial cells, increased proinflammatory cytokine concentration, increased blood-brain barrier (BBB) permeability, and leukocyte invasion [1-3]. Numerous reports have demonstrated that neuroinflammation contributes to the causation and aggravation of neurodegenerative diseases [4-6]. The inflammatory mediators, such as interleukin-1 $\beta$ (IL-1 $\beta$ ), interleukin-6 (IL-6), tumor necrosis factor- $\alpha$ (TNF- $\alpha$ ), chemokines and oxygen free radicals are assumed to stimulate signaling pathways in a pathological cascade to result in neurodegenerative diseases [7-14].

Cathepsins, a large group of lysosomal proteases, have been found to participate in the neuroinflammatory processes [15-21]. According to their catalytic mechanism, they are further defined as cysteine (cathepsin B, C, H, L, $\mathrm{S}, \mathrm{Z}$, and so on), aspartic (cathepsin D, and so on) and serine proteases (cathepsin G, and so on) [22]. The cysteine cathepsins representing the major group of these enzymes are synthesized as inactive preproenzymes $[23,24]$. During the passage to the endoplasmic reticulum, the prepeptide is removed and the procathepsin undergoes proteolytic processing to the mature enzyme in the lysosomal compartment. Besides their physiological roles in cellular protein metabolism, some cysteine cathepsins are involved in several pathological processes, especially in the neuroinflammatory processes of neurodegenerative diseases represented by a tissueand cell-specific expression pattern [25-29].

Cathepsin C (Cat C, or dipeptidyl peptidase I, DPPI), which belongs to cysteine cathepsins with a molecular mass of about $200 \mathrm{kDa}$, has been found constitutively expressed in a variety of tissues in mammals with the highest levels in lungs, kidneys, liver and spleen, but relatively low in the brain [30-34]. Cat $C$ functions as a key enzyme in the activation of granule serine proteases in cytotoxic $\mathrm{T}$ lymphocytes, natural killer cells (granzymes A and B), mast cells (chymase and tryptase) and neutrophils (cathepsin G, proteinase 3, and elastase) [35-37]. The roles of Cat $C$ and the activated serine proteases in modulating the inflammatory responses have been assessed in a number of inflammation models. For instance, Cat $\mathrm{C}$ knockout mice are completely resistant to the acute arthritis induced by anti-type II collagen antibodies and showed a high degree of protection in a collagen-induced rheumatoid arthritis model [38,39]. In addition, the inflammatory cells infiltration and inflammatory cytokines production have been shown to be decreased in Cat $\mathrm{C}$ knockout mouse models of asthma, chronic obstructive pulmonary disease (COPD), sepsis and abdominal aortic aneurysms [40-43]. Based on these studies, we hypothesized that $\mathrm{Cat} C$ in the central nervous system (CNS) might play a similar role in neuroinflammation. In this regard, we have found that Cat $\mathrm{C}$ promoted the brain demyelination in cuprizone-treated mice in our preliminary study (unpublished data). Until now, the Cat $\mathrm{C}$ expression has been studied only on the mRNA level in the homogenized brain tissue [32-34], the expression pattern and cellular localization of $\mathrm{Cat} C$ in the brain, as well as the functional role of $\mathrm{Cat} C$ in neuroinflammation still remain unclear.

In this study, we examined the expression pattern and cellular localization of Cat $C$ in the brain in lipopolysaccharide (LPS)-induced neuroinflammation. We further investigated the expression, release and enzymatic activity of microglial Cat $C$ in response to LPS and proinflammatory cytokines IL-1 $\beta$, IL- 6 stimulations. We found the brain Cat $C$ expression was markedly enhanced in LPSinduced neuroinflammation, and LPS and proinflammatory cytokines could induce the expression, release and upregulate the enzymatic activity of Cat $\mathrm{C}$ in microglial cells.

\section{Materials and methods}

Animals

Eight-week-old C57BL/6 J mice weighing 25 to $30 \mathrm{~g}$ were used in the experiments. Animals were housed in groups of five per cage in a $22 \pm 2^{\circ} \mathrm{C}$ and $45 \sim 65 \%$ relative humidity environment under a normal light cycle room (12-h light/12-h dark; 8:00 a.m. light on 8:00 p.m. light off). All animals had free access to food and water. All procedures were in accordance with the Dalian Medical University guidelines for the proper care and use of laboratory animals and were approved by the Laboratory Animal Care and Use Committee of Dalian Medical University.

\section{Lipopolysaccharide-induced treatment}

LPS (Escherichia coli, serotype 055:B5, Sigma-Aldrich Chemical Corp., St. Louis, MO. USA) was used to induce an inflammatory response. LPS was injected intraperitoneally at a dose of $5 \mathrm{mg} / \mathrm{kg}$ dissolved in sterile, endotoxin-free $0.9 \%$ saline vehicle. Control injections were equivolume vehicle. The dosage of LPS was based on a previous study of LPS-induced neurotoxicity [44].

\section{Tissue preparation}

At the time points of one hour, six hours, twelve hours, twenty-four hours, forty-eight hours, seventy-two hours, seven days and ten days after LPS injection, mice were anesthetized with diethyl ether and perfused with $4 \%$ paraformaldehyde solution. The brains were removed and postfixed with the same fixative overnight. Brains 
were then cryoprotected overnight in phosphate buffered saline (PBS) containing 20\% sucrose, embedded in optimal cutting temperature (OCT) compound (McCormick Scientific, St. Louis, MO, USA), and serial $18 \mu \mathrm{m}$ sagittal sections were made with a cryostat (Leica CM $3050 \mathrm{~S}$, Leica Microsystems AG, Wetzlar, Germany) and used for the immunohistochemical (IHC) and in situ hybridization (ISH) studies.

\section{In situ hybridization}

In situ hybridization (ISH) was performed as described previously [45]. We used digoxigenin (DIG)-labeled Cat C (NM_009982, 193-1324 bp), IL-1ß (NM_008361, 423$880 \mathrm{bp}$ ), TNF- $\alpha$ (NM_013693.2, 575-1607 bp) and inducible nitrite oxide synthase (iNOS) (NM_010927.3, 1921$2827 \mathrm{bp}$ ) cRNA probes. After hybridization of antisense cRNA probes, samples were incubated overnight with alkaline phosphatase-conjugated anti-DIG antibody (Roche, Basel, Switzerland) at $4^{\circ} \mathrm{C}$. Color development was achieved by incubation with 4-nitro blue tetrazolium chloride/5-bromo-4-chloro-3-indolyl-phosphate (NBT/ $\mathrm{BCIP)}$ for sixteen hours at room temperature. Some sections were counterstained with Nuclear Fast Red for observation and analysis. Others were processed for ionized calcium binding adapter molecule 1 (Iba-1) immunohistochemistry (IHC) after ISH. Images were captured using the Nikon digital camera system (DS-Fil, Nikon Corp., Tokyo, Japan) in combination with microscopy (Nikon Eclipse $80 \mathrm{i})$. The number of cells expressing IL-1 $\beta$, iNOS mRNAs was counted with use of image 1.41 (National Institutes of Health). Three sections from each mouse (with five mice per condition) were used for analysis.

\section{Immunohistochemical staining}

IHC was performed as described by Ma et al. [46]. The following antibodies were used: mouse anti-NeuN monoclonal antibody (1:1000, Chemicon, Temecula, CA, USA), rabbit anti-GFAP polyclonal antibody (1:1000, Dako, Glostrup, Denmark), rabbit anti-Iba1 polyclonal antibody (1:500, Wako, Osaka, Japan), goat anti-Cat C antibody (1:100, R\&D Systems, Minneapolis, MN, USA). Secondary antibodies were labeled with Alexa Fluor 594 (Invitrogen Corp., Carlsbad, CA, USA), Alexa Fluor 488 (Invitrogen) or biotin (1:200, Vector Laboratories Inc., Burlingame, CA, USA) antibodies. After IHC reaction, images were captured using the Nikon digital camera system (DS-Fi1) in combination with microscopy (Nikon eclipse 80i).

\section{Cell culture}

Primary microglial cells were harvested from primary mixed glial cell cultures prepared from neonatal C57BL/ $6 \mathrm{~J}$ mice pups as previously reported [44]. In brief, after the meninges were carefully removed, the neonatal brain was dissociated by pipetting. The cell suspension was plated in $10 \mathrm{~cm}$ culture dish at a density of one brain per two dishes in $10 \mathrm{~mL}$ Dulbecco's modified eagle medium (DMEM) (Sigma) containing 10\% fetal bovine serum (FBS) (ICN Biomedicals, Aurora, OH, USA). After fourteen to twenty-one days in vitro, mixed glial cell cultures were dissociated by trypsinization, and the cell suspension was seeded on a petri dish and incubated for thirty minutes in a $\mathrm{CO}_{2}$ incubator. Adherent cells were harvested as primary microglial cells. Microglial cells were reseeded in culture plates. The purity of microglial cells was approximately $99 \%$ as determined by CD11b (rat monoclonal immunoglobulin G (IgG), clone M1/70, Abcam Inc., Cambridge, MA, USA) staining.

The immortalized murine microglial cell line BV-2 was a kind gift from Dr. XF Wu (Dalian Medical University, China) and were maintained in DMEM supplemented with $10 \%$ FBS, $2 \mathrm{mM}$ glutamine and $100 \mathrm{U} / \mathrm{mL}$ penicillin/streptomycin at $37^{\circ} \mathrm{C}$ in $5 \% \mathrm{CO}_{2}$ in a humidified atmosphere.

\section{Nitrite assay}

Primary microglial cells and BV-2 cells were cultured in medium without FBS for twenty-four hours at $1.0 \times 10^{5}$ cells/24-well plate, then treated with LPS $(10 \mathrm{ng} / \mathrm{mL})$, IL-1 $\beta(0.1 \mathrm{ng} / \mathrm{mL})$ or IL-6 $(0.1 \mathrm{ng} / \mathrm{mL})$ for six hours, respectively. After treatment, the nitrite in the culture medium was measured as an indicator of nitric oxide (NO) production. An aliquot of the culture medium was mixed with a volume of Griess reagent (Beyotime Institute of Biotechnology, Jiangsu, China), and the absorbance at the wavelength $540 \mathrm{~nm}$ was determined using a microplate reader (iMark, Bio-Rad Laboratories, Tokyo, Japan). Sodium nitrite at the concentrations of 0 to $100 \mu \mathrm{M}$ was used as a standard to assess nitrite concentrations.

\section{Enzyme-linked immunosorbent assay (ELISA)}

Primary microglial cells and BV-2 cells were cultured in the same condition as above, prior to treatment with various concentrations of LPS $(10,50,100 \mathrm{ng} / \mathrm{mL}), \mathrm{IL}-1 \beta$ $(0.1,1,10 \mathrm{ng} / \mathrm{mL})$, IL-6 $(0.1,1,10 \mathrm{ng} / \mathrm{mL})$ for six hours, respectively. After treatment, mouse Cat C ELISA kit (R\&D) was used for the quantitative measurement of Cat $\mathrm{C}$ in the cell lysates and culture medium.

\section{Semi-quantitative reverse transcription polymerase Chain reaction (RT-PCR) analysis}

The treatment of BV-2 cells was the same as that in ELISA. After treatment, total RNA from cells was extracted using Trizol reagent (Invitrogen) according to the manufacturer's protocol. Reverse transcription was performed using SuperScript II Reverse Transcriptase (Invitrogen). Primers sequences: Cat C: forward: 5' 
CAGAGGCCACACAGCTATCA 3', reverse: 5' GCATGATTTGTCAGCTCGAA 3' (891 bp); $\beta$-actin: forward: 5' ATCATGTTTGAGACCTTCAACA 3', reverse: 5' CATCTCCTGCTCGAAGTCTA 3' (318 bp). All primers were synthesized by Takara Biotechnology Co. Ltd. (Dalian, China). The PCR profile consisted of an initial melting step of one minute at $95^{\circ} \mathrm{C}$, followed by thirty cycles of thirty seconds at $95^{\circ} \mathrm{C}$, fifteen seconds at $56^{\circ} \mathrm{C}$ and forty-five seconds at $72^{\circ} \mathrm{C}$, and a final elongation step of one minute at $72^{\circ} \mathrm{C}$. PCR products were separated by $1.2 \%$ agarose gel eletrophoresis. Gels were stained with ethidium bromide and analyzed under ultraviolet light. The level of $\mathrm{Cat} C$ gene expression was calculated as the gray ratio of PCR product of Cat $C$ over the internal standard ( $\beta$-actin). The gray values of PCR product bands were obtained from a computerized image analysis using Gel-pro Analyzer version 4.5 software (Media Cybernetics, Silver Spring, MD, USA).

\section{Cathepsin C enzymatic activity assay}

BV-2 cells were cultured in the same condition as above, and then treated with LPS $(10,50 \mathrm{ng} / \mathrm{mL}), \mathrm{IL}-1 \beta(0.1$, $10 \mathrm{ng} / \mathrm{mL})$, IL-6 $(0.1,10 \mathrm{ng} / \mathrm{mL})$ for six hours, respectively. Cat $\mathrm{C}$ enzymatic activity in cell lysates and culture medium was determined by cellular Cat $\mathrm{C}$ assay kit (Genmed Scientifics Inc., Arlington, MA, USA). The procedures were performed according to manufacturer's protocols. All samples (50 $\mu \mathrm{g}$ Cat $\mathrm{C}$ protein/well in 96-well plate) were incubated with the substrate, H-Gly-Phe-pNitroaniline, at $37^{\circ} \mathrm{C}$ for six hours. The product formed was detected by measuring the absorbance at the wavelength $405 \mathrm{~nm}$ with microplate reader (iMark, Bio-Rad). Data were presented as relative folds to untreated control.

\section{Statistical analysis}

Data were expressed as mean + standard error of the mean (SEM) from three independent experiments. All statistical analyses were performed using the Statistical Package for Social Sciences (Version 11.5). The data were evaluated for statistical significance with paired $t$ test. $P<0.05$ was considered statistically significant.

\section{Results}

Systemic lipopolysaccharide injection induced the neuroinflammation

In our study, a single intraperitoneal injection of LPS $(5 \mathrm{mg} / \mathrm{kg})$ did not result in death, but caused apparent systemic inflammation reflected by a fever and hepatosplenomegaly after LPS injection. To investigate whether LPS-evoked systemic inflammation affected the brain, we first examined the behavior of microglial cells by detection of morphology after systemic administration of LPS. Iba-1 (ionized calcium binding adaptor molecule-1) was used as a specific marker for microglial cells and monocytes. The IHC staining (Figure 1A and B) showed that compared to control mice (Figure 1A), Iba-1 positive cells displayed thicker and shorter processes, markedly enlarged cell bodies at six hours after LPS injection (Figure 1B). The apparent alterations of Iba-1 positive cells indicate the sufficient activation of microglial cells in the brain by systemic LPS injection, which was present for seven days after LPS injection.

To investigate whether LPS systemic injection causes inflammatory mediators release in the brain, we next examined the expressions of proinflammatory cytokines IL- $1 \beta$ and TNF- $\alpha$ mRNAs in the brain at the different time points following LPS injection by using ISH. At the same time, we also examined the level of inducible nitric oxide synthase (iNOS) mRNA expression, since nitric oxide (NO) production has been widely regarded as representative of inflammatory activation $[47,48]$, and iNOS is responsible for generating high levels of $\mathrm{NO}$ in activated macrophages/monocytes. We found LPS-induced expressions of IL- $1 \beta$, TNF- $\alpha$ mRNAs, as well as iNOS mRNA were different in temporal and spatial patterns (Figure $1 \mathrm{C}$ to $\mathrm{H}$ ). At one hour after LPS injection, the expressions of IL-1 $\beta$ (Figure 1C) and TNF- $\alpha$ mRNAs (data not shown) appeared in the choroid plexus, the circumventricular organs, and the leptomeninges. At six hours, the expressions of these cytokines increased dramatically (Figure 1D and G). Peak cytokines were captured at twelve hours after LPS injection and distributed throughout the entire brain (Figure 1G). At twenty-four hours, the expression of L-1 $\beta$ mRNA (Figure 1G) or TNF- $\alpha$ mRNA (data not shown) decreased significantly and became barely detectable, compared to the expression at six hours and twelve hours. While iNOS mRNA expression started to appear in choroid plexus (Figure 1E) at twenty-four hours after LPS injection. The iNOS mRNA expression was detected in the brain parenchyma (Figure 1F) and throughout the brain at forty-eight hours and maximized at seventy-two hours. On the seventh day after LPS injection, iNOS mRNA expression decreased significantly compared to the expression at forty-eight hours and seventy-two hours (Figure 1H). Our data indicate that induced IL- $1 \beta$ and TNF- $\alpha$ mRNAs were expressed earlier than iNOS mRNA, however, the iNOS mRNA expression lasted longer than IL$1 \beta$ and TNF- $\alpha$ mRNAs after LPS injection. The presence of highly activated microglial cells and the synthesis of proinflammatory mediators in the brain demonstrated that systemic LPS injection indeed induced neuroinflammation.

\section{Neuroinflammation-induced cathepsin $\mathrm{C}$ expression in the} brain

Previous studies have shown that Cat $\mathrm{C}$ plays crucial roles in the processes of peripheral inflammation, but 

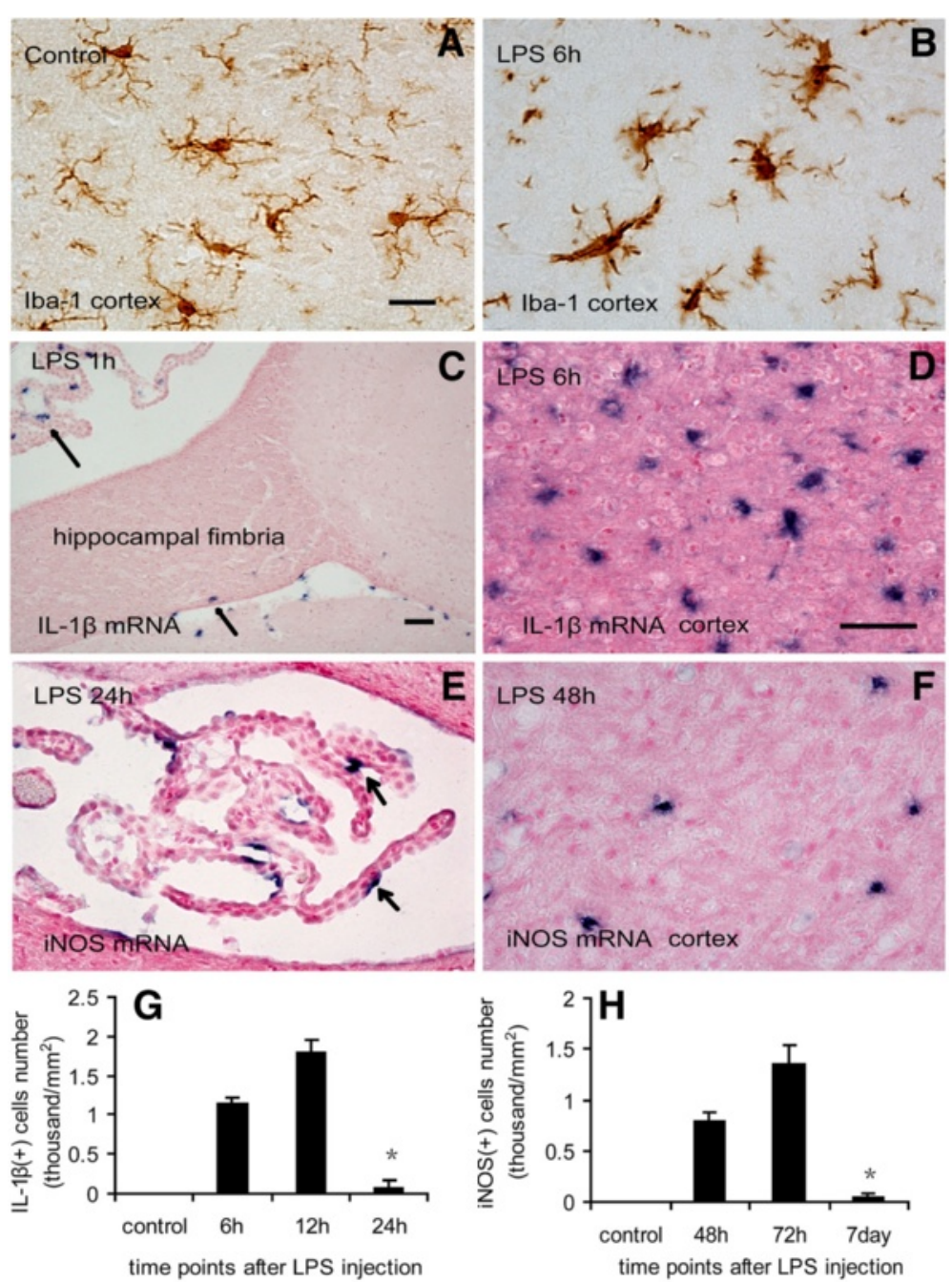

Figure 1 Activation of microglial cells and the expression of proinflammatory mediators following LPS injection. Iba- $1 \mathrm{IHC}$ staining showed the processes of microglial cells are ramified in control (A). At six hours after LPS injection the processes of microglial cells became thicker and shorter, and cell bodies became larger (B). ISH results showed IL-1 3 mRNA expression appeared in choroid plexus and hippocampal fimbria at one hour after LPS injection (arrows in C), and occurred extensively in the whole brain at six hours after LPS injection, here is an example in cerebral cortex (D). iNOS mRNA expression appeared only in choroid plexus at twenty-four hours after LPS injection (arrows in E), and then developed in the cerebral cortex (F). Quantitative analysis of the number of IL-1 $\beta$ mRNA- (G) and iNOS mRNA- (H) expressing cells in the cerebral cortex at different time points after LPS injection. ${ }^{*} P<0.05$, compared with six hours, twelve hours (G); forty-eight hours, seventy-two hours (H). Scale bar $=20 \mu \mathrm{m}(\mathrm{A}, \mathrm{B}, \mathrm{F}) ; 50 \mu \mathrm{M}(\mathrm{C}) ; 50 \mu \mathrm{M}(\mathrm{D}, \mathrm{E}) . \mathrm{n}=5$ per condition. Cat C, cathepsin C; lba-1, ionized calcium binding adaptor molecule-1; IHC, immunohistochemistry; iNOS, inducible nitric oxide synthase; ISH, in situ hybridization; LPS, lipopolysaccharide.

the expression pattern of Cat $\mathrm{C}$ in the CNS has not been reported. Thus, first, we examined the expression pattern of Cat $\mathrm{C}$ in control mice by using IHC staining and ISH staining. We found that Cat C IHC staining was predominantly expressed in the pyramidal neurons of the hippocampal CA2 region (Figure $2 \mathrm{C}$ to $\mathrm{D}$ ), the choroid plexus in ventricles (Figure $2 \mathrm{~A}$ and $\mathrm{C}$ ), the leptomeninges (Figure $2 \mathrm{C}$ ) and the vascular cells (Figure 2C). A few Cat Cexpressing neurons in the vicinity of the pyramidal neuron layer in the CA2 region appeared to be interneurons (Figure 2C). Dense Cat C-labeling granules scattered in the cytoplasm and processes, sparing the nucleus (Figure 2D). No obvious Cat $\mathrm{C}$ labeling was found in other brain regions. The ISH results showed that the expression pattern of Cat $\mathrm{C}$ mRNA was consistent with that of Cat $\mathrm{C}$ protein (Figure 2A to B). These findings indicate that the Cat $\mathrm{C}$ gene is expressed at low level in the brain under physiological conditions.

Next, we tested Cat $\mathrm{C}$ expression in the brain by examining regional distribution and cellular localization of 


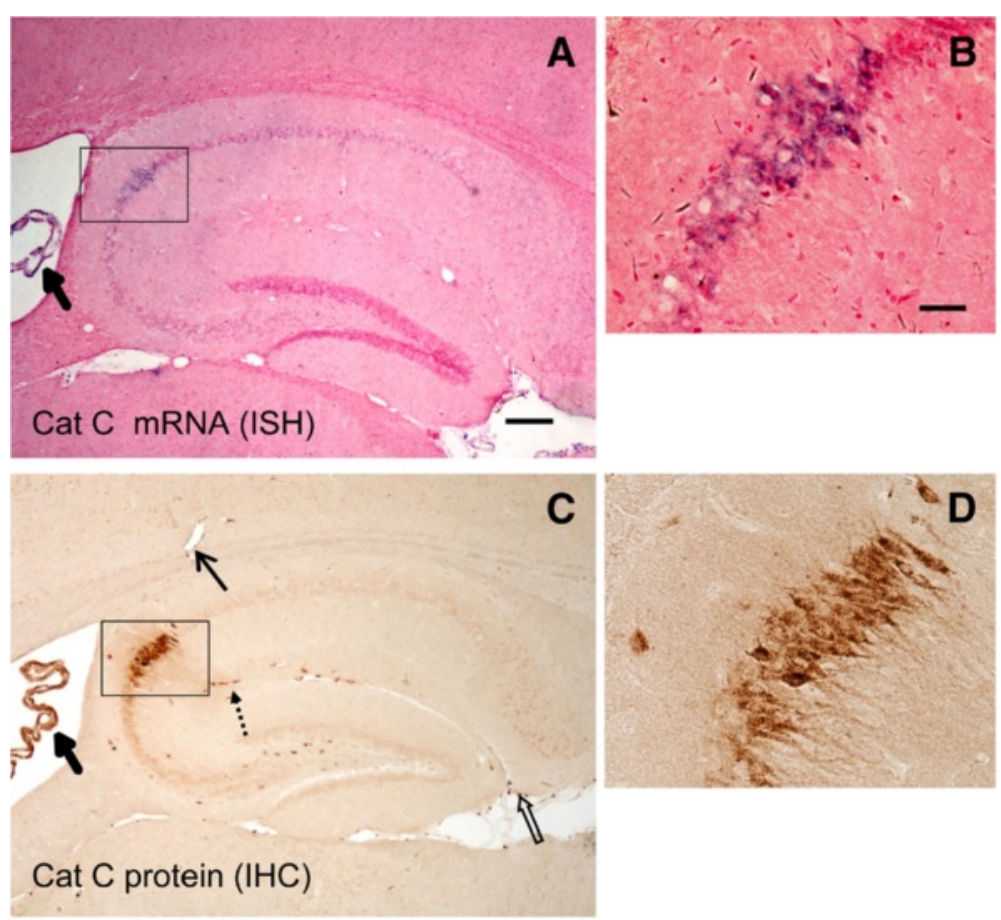

Figure 2 The expression pattern of Cat $\mathbf{C}$ mRNA and protein in the control brain. ISH (A and $\mathbf{B})$ and IHC (C and $\mathbf{D})$ staining were performed in control mice. The rectangles in $A$ and $C$ which included the $C A 2$ area were enlarged into $B$ and $D$, respectively. Cat $C$ gene was predominantly expressed in the CA2 neurons of the hippocampus (B and D), interneurons (dotted arrow in C), choroid plexus (thick solid arrows in $A$ and $C$ ), leptomeninges (open arrow in C) and vascular cells (thin solid arrow in C). Scale bar $=100 \mu \mathrm{m}(\mathrm{A}, \mathrm{C}) ; 20 \mu \mathrm{M}(\mathrm{B}, \mathrm{D}) . \mathrm{n}=5$ per condition. Cat $\mathrm{C}$, cathepsin $\mathrm{C} ; \mathrm{IHC}$, immunohistochemistry; ISH, in situ hybridization.

Cat $\mathrm{C}$ at different time points following LPS injection. At six hours after LPS injection, in addition to the previously reported Cat $\mathrm{C}$ positive cells in the CA2 region of the hippocampus under physiological conditions, a large number of Cat $\mathrm{C}$ immunopositive cells with neuronal morphology were found to distribute evenly in the cerebral cortex (Figure 3A). At twenty-four hours after LPS injection, we detected Cat $\mathrm{C}$ immunopositive signals in the cells with glial morphology in the hippocampus, cortex, substantia nigra $(\mathrm{SN})$, striatum, cerebellum, brain stem and other brain regions (Figure $3 G$ to I). Thus, we concluded that LPS injection for twenty-four hours could induce a global expression of the Cat $\mathrm{C}$ immunopositive signals, presumably in both neuronal and glial cells.

To confirm the phenotype in Cat $\mathrm{C}$ immunopositive cells, we performed double stainings in the following combination: Cat $\mathrm{C}$ (IHC) and NeuN (neuronal marker, IHC); Iba1 (microglial cell marker, IHC) following Cat C (ISH); GFAP (astrocyte marker, IHC) following Cat C (ISH). At six hours after LPS injection, almost all the Cat $\mathrm{C}$ positive cells in the cortex expressed NeuN (Figure 3A to C), while at twentyfour hours, the majority of Cat $\mathrm{C}$ mRNA positive cells were colabeled with Iba-1 (Figure 3J and K), but we did not find colocalization of Cat C mRNA and GFAP (data not shown). These data indicate that six hours after LPS injection Cat C expressed in cortical neurons; twenty-four hours after, microglial cells initiated to express Cat $\mathrm{C}$. We found neuronal Cat $\mathrm{C}$ expression became faint on the seventh day, undetectable on the tenth day after LPS injection (data not shown). Microglial Cat $\mathrm{C}$ expression decreased significantly and became almost undetectable at seventy-two hours after LPS injection (data not shown). These observations suggest that the time course of Cat $\mathrm{C}$ expression in neurons and microglial cells is different.

To determine whether the transcriptional level of the Cat $\mathrm{C}$ gene corresponds to the reported expression of Cat $\mathrm{C}$ protein in the brain, we used ISH to examine the levels of Cat $\mathrm{C}$ mRNA expression at same time points following LPS injection. ISH results showed alterations in the expression pattern of Cat $C$ mRNA were similar to those of the Cat $C$ protein (Figure $3 \mathrm{D}$ to $\mathrm{F}$ ).

Taken together, the data indicate that LPS-induced neuroinflammation triggered a transient induction of Cat $\mathrm{C}$ expression in neurons and microglial cells with differential temporal and spatial patterns.

\section{Lipopolysaccharide and proinflammatory cytokines induced the expression of cathepsin $\mathrm{C}$ gene in vitro} In our present study, we systemically administrated a highdose LPS (5 mg/kg) to mimic deleterious systemic infections. LPS administration activated microglial cells, induced proinflammatory mediators, Cat $\mathrm{C}$ mRNA and protein 


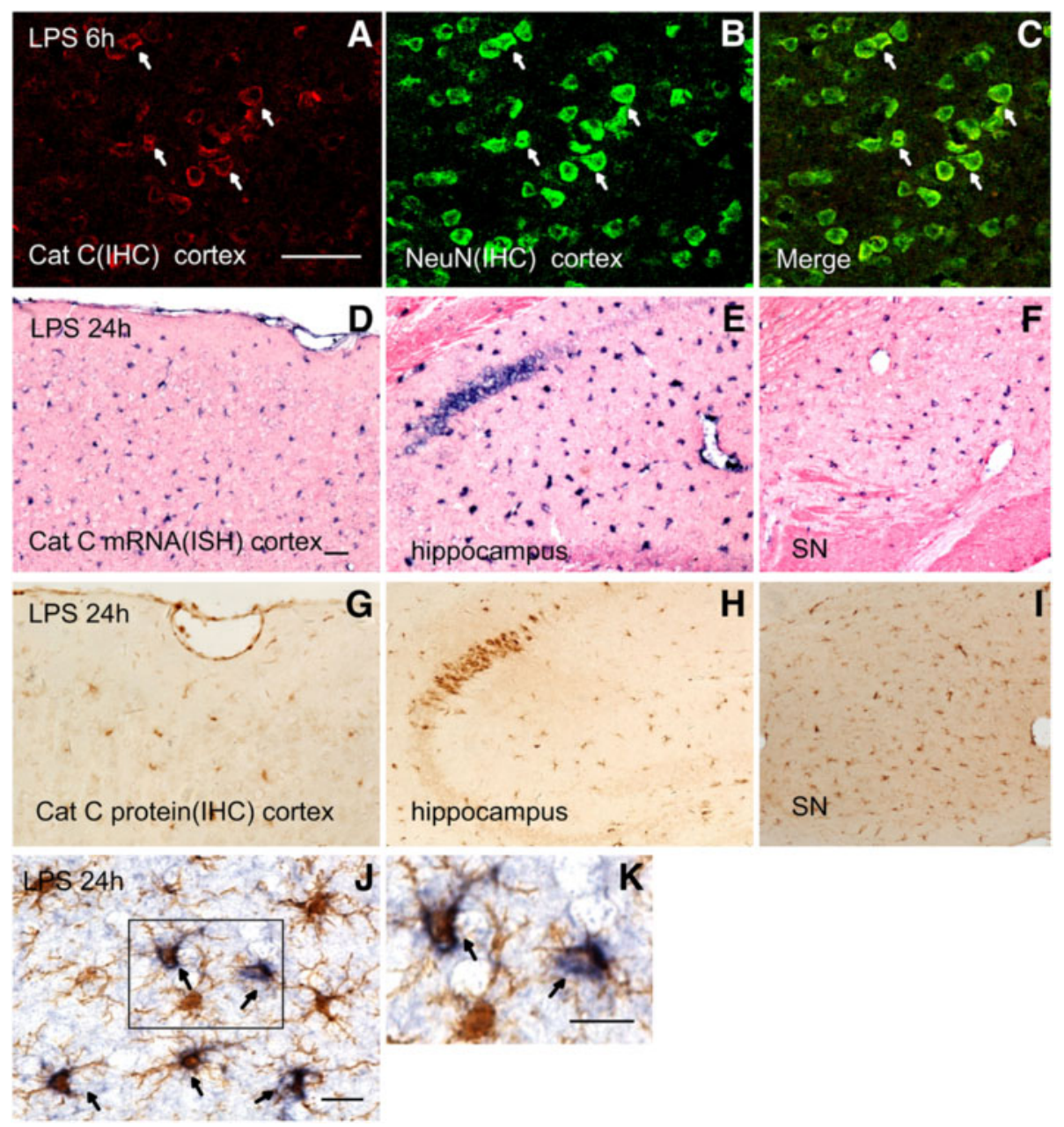

Figure 3 The expression of Cat C was induced in the brain at six hours and twenty-four hours following LPS injection. $I H C$ double staining showed that the Cat C expression was induced in cortical neurons at six hours after LPS injection (A to C). After LPS injection for twentyfour hours, the expression of Cat C mRNA and protein was induced further and distributed throughout the entire brain, such as the cortex (D and $\mathbf{G})$, hippocampus (E and $\mathbf{H})$ and SN (F and $\mathbf{I})$. Double staining of Iba-1 (IHC) and Cat C (ISH) showed that Cat C expression was induced in

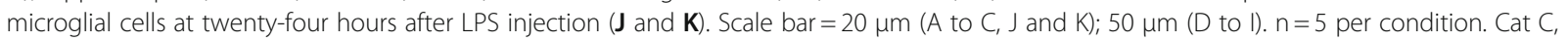
cathepsin C; Iba-1, ionized calcium binding adaptor molecule-1; IHC, immunohistochemistry; ISH, in situ hybridization; LPS, lipopolysaccharide. SN, substantia nigra.

expressed in the brain. Apart from that, we also noticed that peak of IL-1 $\beta$, IL- 6 and TNF- $\alpha$ mRNAs expressions appeared at twelve hours after LPS injection, while significantly higher Cat $C$ expression in microglial cells was detected at twenty-four hours after LPS injection. This time difference in expression suggests that proinflammatory cytokines might induce Cat $C$ expression in microglial cells. Furthermore, Rao et al. [32] previously reported that the treatment of lymphocytes with interleukin-2 (IL-2) resulted in a significant increase in Cat $\mathrm{C}$ mRNA levels by Northern analyses. Therefore, we hypothesized an inducible effect of proinflammatory cytokines on Cat $\mathrm{C}$ expression in the microglial cells.

To test our hypothesis, we examined the NO concentration in the culture medium and Cat $\mathrm{C}$ protein and mRNA expression in cell lysates and culture medium of the BV-2 cells or primary microglial cells treated with various concentrations of LPS $(10,50,100 \mathrm{ng} / \mathrm{mL}), \operatorname{IL}-1 \beta(0.1,1,10 \mathrm{ng} /$ $\mathrm{mL})$ or IL-6 $(0.1,1,10 \mathrm{ng} / \mathrm{mL})$. We first determined the NO level in the culture medium following treatment with LPS $(10 \mathrm{ng} / \mathrm{mL})$, IL-1 $\beta(0.1 \mathrm{ng} / \mathrm{mL})$ or IL-6 $(0.1 \mathrm{ng} / \mathrm{mL})$. There was a significantly higher level of NO in the culture medium of both BV-2 cells and primary microglial cells after treatments, compared to untreated cells $(P<0.01)$ (data not shown). This indicates that these inflammatory stimulators successfully activated microglial cells, even at the lowest concentrations.

Then we examined Cat $C$ protein levels in cell lysates and culture medium by ELISA. Compared to untreated cells cultured, Cat $\mathrm{C}$ protein expression was increased in 
a dose-dependent manner, in either BV-2 cell lysates or primary microglial cell lysates, following six-hour LPS treatment (Figure 4A). Similar results were seen in cell lysates with IL-1 $\beta$ or IL- 6 treatment (Figure $4 \mathrm{~B}$ and C). In contrast, the secretion of $C$ at $C$ in the medium was affected to various extents (Figure $4 \mathrm{D}$ to $\mathrm{F}$ ).

Next, Cat C mRNA expression in stimulated BV-2 cells was measured by semi-quantitative RT-PCR, which corresponds with $C$ at $C$ protein increases in microglial cells. We saw lower Cat $C$ mRNA expression in untreated cells (Figure 5A), while a significantly higher and dosedependent expression was seen in LPS (Figure 5A and D), IL-1 $\beta$ (Figure $5 \mathrm{~B}$ and E) or IL-6 (Figure $5 \mathrm{C}$ and F) treated cells, suggesting that the expression of Cat $C$ gene was subjected to transcriptional regulation.

Taken together, the expression and release of Cat $C$ in response to LPS, IL-1 $\beta$ and IL-6 stimulation in vitro support the notion that in the brain, Cat $\mathrm{C}$ expression could also be induced by LPS and proinflammatory cytokines.

\section{Lipopolysaccharide and proinflammatory cytokines} upregulated cathepsin $C$ enzymatic activity in vitro Cat $\mathrm{C}$ functions as a key enzyme in the activation of granule serine proteases in inflammatory cells. Once activated, serine proteases will trigger a series of reactions leading to tissue damage and chronic inflammation. Therefore, it is essential to investigate the alterations of Cat $\mathrm{C}$ enzymatic activity in neuroinflammation. In order to know whether the Cat $C$ induced by LPS and proinflammatory cytokines has enzymatic activity, we tested Cat $\mathrm{C}$ activity in BV-2 cell lysates and culture medium following six-hour treatment with LPS (10, $50 \mathrm{ng} / \mathrm{mL}), \mathrm{IL}-1 \beta(0.1,10 \mathrm{ng} / \mathrm{mL})$, or IL-6 $(0.1,10 \mathrm{ng} /$ $\mathrm{mL})$. The results showed that LPS (Figure 6A), IL-1 $\beta$ (Figure 6B) or IL-6 (Figure 6C) significantly upregulated Cat $C$ enzymatic activity in cell lysates, whereas the increase of Cat $\mathrm{C}$ enzymatic activity in the medium was only detected with LPS treatment (Figure 6A), no significant increase of Cat $\mathrm{C}$ enzymatic activity was found with IL- $1 \beta$ or IL- 6 treatment (Figure $6 B, C$ ).

\section{Discussion}

The systemic inflammation may induce neuroinflammation by producing circulating cytokines, which in return will have an important impact on the CNS [21,49]. Alterations in brain metabolism and function were observed in almost $70 \%$ of septic patients or in animals subjected to systemic inflammation or septic shock $[14,50,51]$. LPS, a component of the cell wall of gramnegative bacteria, could stimulate immune cells to

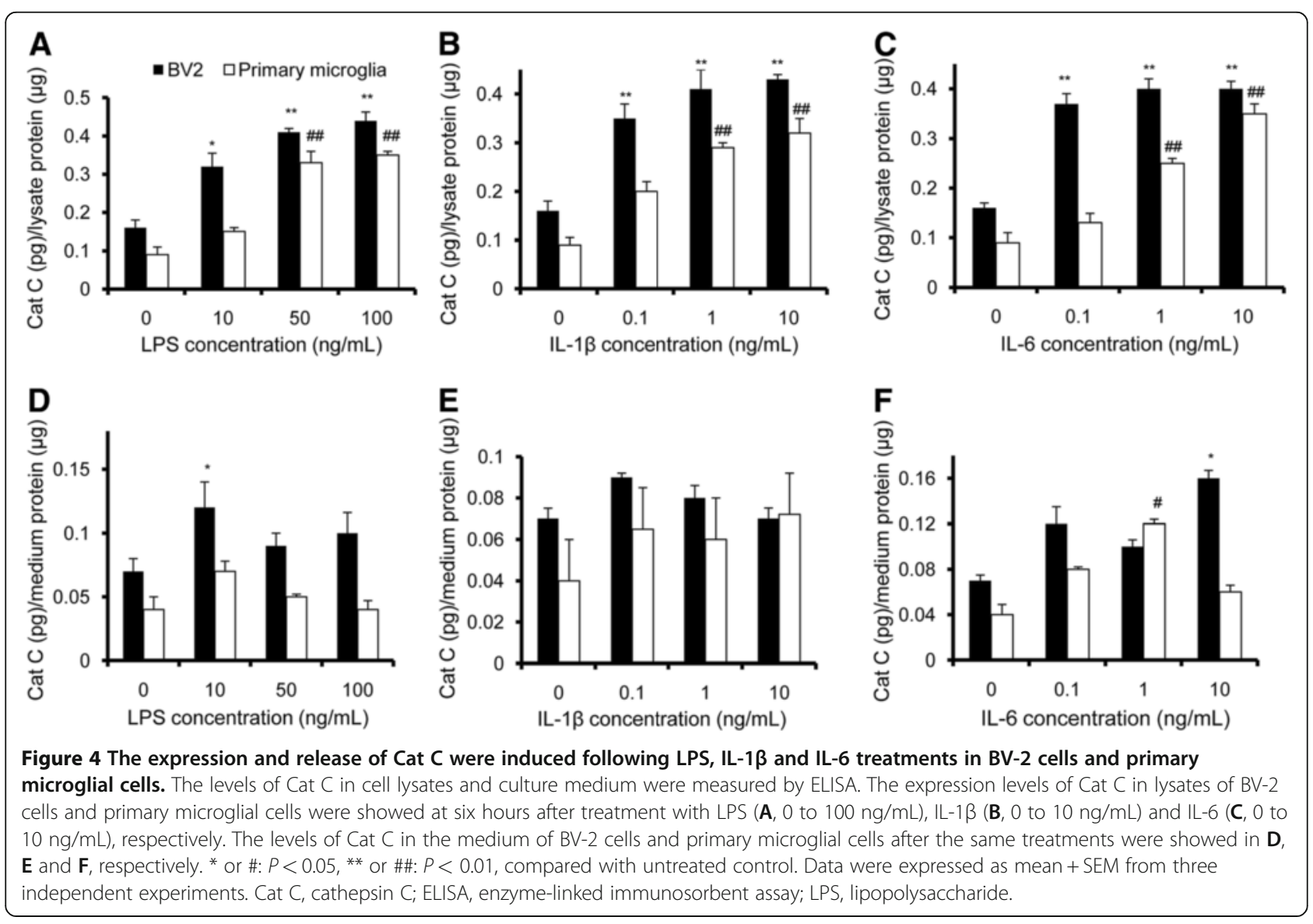



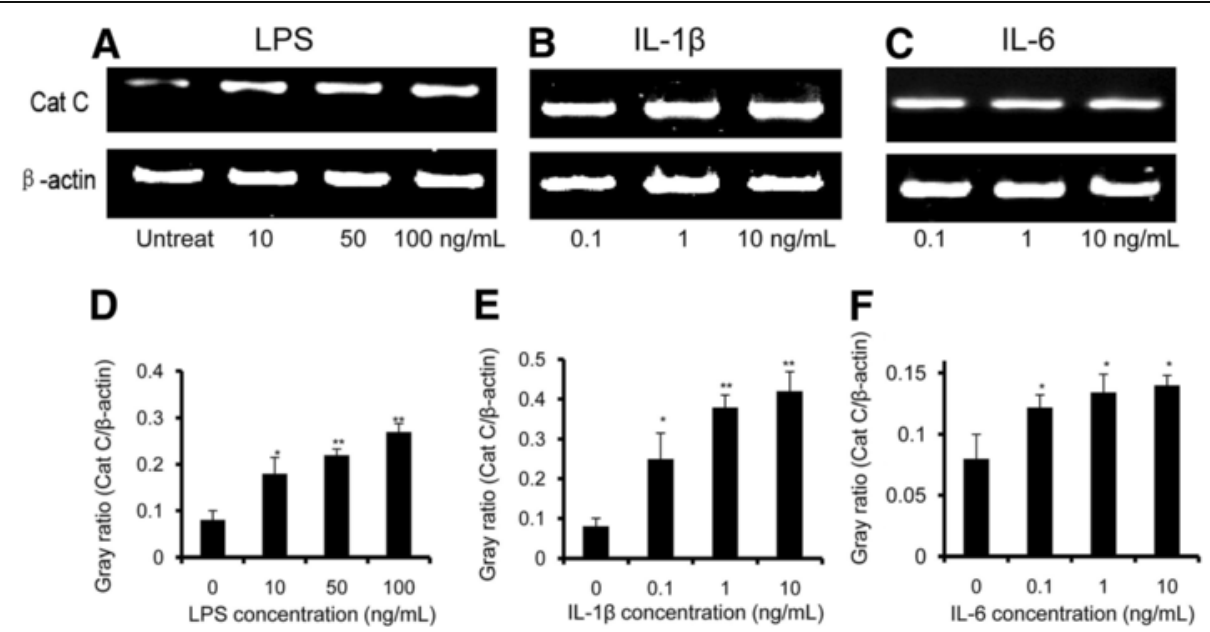

Figure 5 The expression of Cat C mRNA was induced following LPS, IL-1 $\beta$ and IL- 6 treatments in BV-2 cells. The levels of Cat $C$ mRNA were measured by RT-PCR after treatments of LPS (0 to $100 \mathrm{ng} / \mathrm{mL}$ ), IL-1 1 (0 to $10 \mathrm{ng} / \mathrm{mL}$ ) and IL-6 (0 to $10 \mathrm{ng} / \mathrm{mL})$. The example of PCR product band and averaged gray ratio at the each of treatments were shown in (A) and (D), (B) and (E), (C) and (F), respectively. Note a dose-dependent expression of $C$ at $C$ mRNA was found in three groups of treatments. ${ }^{*}: P<0.05,{ }^{* *}: P<0.01$, compared with untreated control. Data were expressed as mean + SEM from three independent experiments. Cat C, cathepsin C; LPS, lipopolysaccharide; RT-PCR, reverse transcription polymerase chain reaction.

release an array of proinflammatory mediators resulting in a septic inflammatory response [52-57]. Most effects by peripherally administered LPS are likely mediated through LPS receptors outside the BBB. LPS is a macromolecule with a molecular weight of approximately 50 to $100 \mathrm{kDa}$ [58], only a minimal amount of LPS is capable to cross the BBB [59]. The mechanisms by which LPS is transduced into the CNS and causes neuroinflammation are not fully understood. Based on our observation and other studies, we considered the following possibilities: (1) Circulating LPS might enter the brain parenchyma through circumventricular organs, choroid plexus and leptomeninges. These structures which are enriched with the LPS receptor, CD14 and toll-like receptor 4 (TLR4) [60], will allow a rapid transcription of proinflammatory cytokines across the brain parenchyma. We have consistently observed the expressions of IL- $1 \beta$, TNF- $\alpha$ in these structures at one hour after systematic LPS injection, supporting this possibility. (2) Circulating LPS and proinflammatory cytokines together act on the brain microvasculature leading to the transcriptional activation of a wide range of proinflammatory cytokines and chemokines [61], which may cross the BBB to mediate central effects. (3) Circulating LPS may enter the brain directly through opening of the BBB, but only in cases of brain infections or deleterious systemic infections associated with the opening of the BBB. In our present study, we administrated LPS at a dose of $5 \mathrm{mg} / \mathrm{kg}$, which was reported to induce serious systemic infection [44]. It has been reported that astrocytes were severely damaged by LPS in the SN [62]. Since astrocytes are a structural component of the $\mathrm{BBB}$, the permeability of the $\mathrm{BBB}$

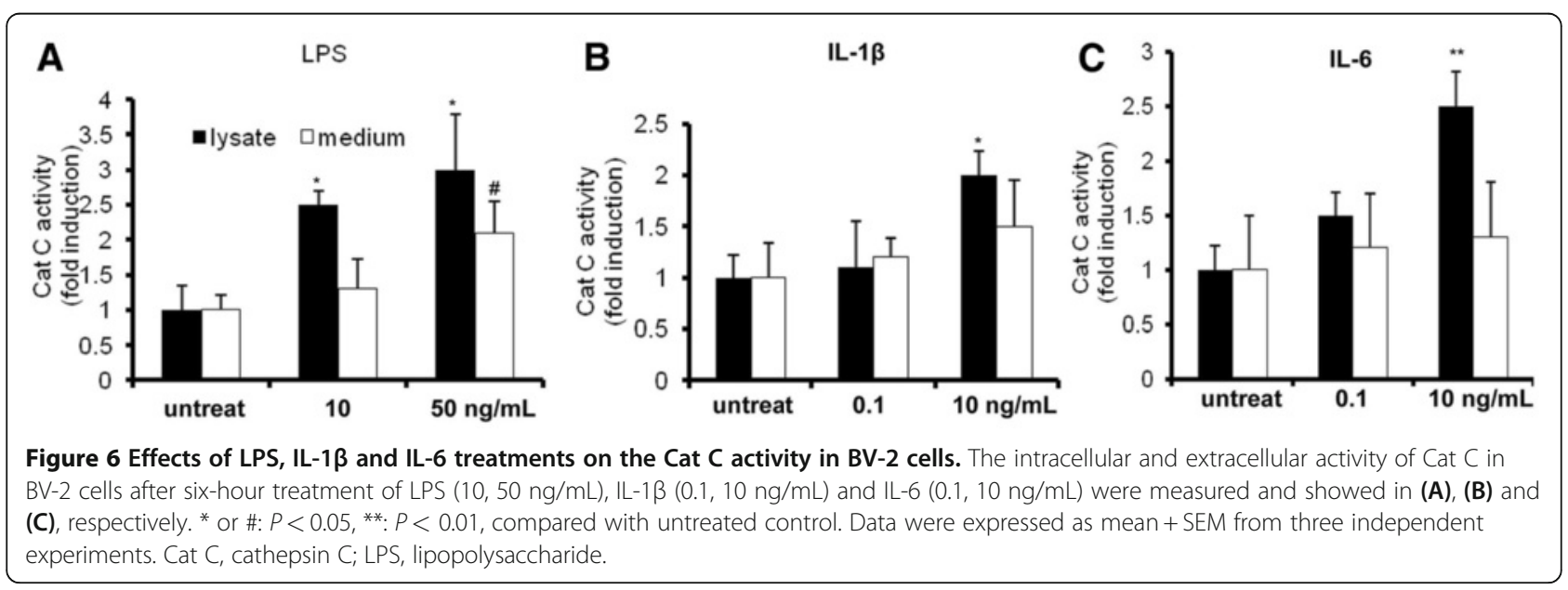


could be increased due to the damaged astrocytes. (4) The inflammatory cells of the bloodstream activated by systemically administrated LPS may enter the brain and cause neuroinflammation.

Much evidence suggests that LPS-induced systemic inflammation can activate microglial cells (resident innate immune cells) and neurons in the brain [34,63,64]. And the activated microglial cells and neurons could release cathepsins from their lysosomes, resulting in the neuronal death and neurodegeneration [15-21]. Cat $C$ is the physiological activator of serine proteases from immune and inflammatory cells vital for defense of an organism. Dominant-negative mutations of human Cat $\mathrm{C}$ gene are linked to the Papillon-Lefèvre syndrome [65], a disease characterized by early periodontitis, palmoplantar hyperkeratosis, and a predisposition to bacterial infections. This indicates that Cat $\mathrm{C}$ plays an important role in the immune system. Cat $C$ is differentially expressed in human tissues. Northern blot analysis showed transcripts of Cat C were barely detectable in the brain [32-34]. In our study, ISH and IHC staining revealed the expression of Cat $\mathrm{C}$ mRNA and protein was restricted to the hippocampal CA2 region, choroid plexus, leptomeninges and vascular cells in control mice. To the best of our knowledge, it is the first report of expression pattern of Cat C in the CNS under physiological conditions. However, the functional significance of specific Cat $\mathrm{C}$ expression pattern in the pyramidal neurons of hippocampus still remains unclear.

In our present study, at six hours after LPS injection, a substantial Cat $\mathrm{C}$ expression was found in cortical neurons, the expression was present for ten days, but these neurons did not change the least bit in morphology. These results indicate that a single LPS injection is not sufficient to cause obvious damage to neurons. Furthermore, the Cat $\mathrm{C}$ mRNA and protein expressions were detected in microglial cells throughout the entire brain at twenty-four hours after LPS injection and were present for up to three days, implying a differential time-related regulation of Cat $\mathrm{C}$ expression in neurons and microglial cells in the brain in response to systemic immune challenges. Previous studies reported that several serine proteases expressed in neurons and glial cells, such as thrombin, trypsin-like serine proteases, are involved in modulating neuroinflammation and neuroprotection events in the CNS [66-68]. However, the precise mechanisms for activating these enzymes in brain tissue still remain obscure. Since Cat $\mathrm{C}$ is capable of activating many serine proteases in peripheral tissues, Cat $\mathrm{C}$ is likely to be a good candidate for activating brain serine proteases. In our present study, we cannot define whether the functional significance of an increased Cat $\mathrm{C}$ expression in a neuron is a transiently protective response or a detrimental response to acute inflammation.

In this study, using cell lines and primary cells, we further determined inflammatory factors involved in induction of microglial Cat $\mathrm{C}$ expression and enzymatic activity. We found the Cat $\mathrm{C}$ mRNA and protein expressions in microglial cells were increased dose-dependently upon various inflammatory stimulations (LPS, IL- $1 \beta$ and IL-6). Also, these inflammatory mediators increased the enzymatic activity of Cat $C$ in microglial cells, suggesting increased Cat $\mathrm{C}$ activity could be due to increased mRNA and protein levels. On the other hand, LPS caused Cat $\mathrm{C}$ activity to increase in the culture medium, which could be attributed to increased secretion of active Cat $C$ from microglial cells. Our study suggests regulation of expression, secretion and activity of Cat $\mathrm{C}$ in microglial cells by various inflammatory stimulations that may be present in vivo under various circumstances, for example, CNS injury and nerve degeneration [69-71].

Cat $C$ is synthesized as inactive preprocathepsin $C$ in vivo and is processed into its active mature form by a series of proteolytic cleavages. Some endopeptidases, presumably cathepsin $\mathrm{L}$ or $\mathrm{S}$, are responsible for the activation of Cat $\mathrm{C}$ [72]. Once activated, Cat $\mathrm{C}$ mediates the conversion of granule serine proteases from their inactive (zymogen) into the enzymatically active protease by removing an N-terminal propeptide [38]. Cat C plays an immunoregulatory role through activating serine proteases during inflammation. The findings in Cat $\mathrm{C}$ knockout mice supported the role of $\mathrm{Cat} C$ in modulating inflammatory processes in vivo. Neutrophils of Cat $C$ knockout mice showed very little enzymatic activity of serine proteases and demonstrated a strongly decreased infiltration to the sites of inflammation in either an experimental arthritis model or an asthma model [38,43]. Importantly, this was accompanied by decreased local production of inflammatory chemokines (such as CXCL2) and cytokines (such as TNF- $\alpha$, IL-1 $\beta$, IL6). Based on these studies of Cat $C$ mediating peripheral inflammation and our present findings in CNS, we hypothesize that the functional role of Cat C in LPSinduced neuroinflammation is as follows: the activated microglial cells produce proinflammatory cytokines which may induce Cat $\mathrm{C}$ expression and enzymatic activity; Cat $\mathrm{C}$ further modulates cellular events through activating serine proteases, leading to cytokines amplification. Hence, the interaction between inflammatory cytokines and $C$ at $C$ in the brain may be responsible for the continuous inflammatory cycle in neurodegenerative diseases as well as other neuroinflammation-involved neurological disorders.

\section{Conclusions}

In our current study, we established an animal model of neuroinflammation by LPS systemic administration. We presented data showing the regional distribution and cellular localization of Cat $\mathrm{C}$, a lysosomal cysteine protease, in the brain. Our study demonstrated the alterations of Cat $\mathrm{C}$ in neuroinflammation. We found $\mathrm{Cat} C$ was expressed in the brain at low level under physiological 
conditions. After LPS administration, Cat C expression was induced in neurons and microglial cells at different time points. In vitro preparations, stimulations of LPS and proinflammatory factors IL-1 $\beta$, IL-6 induced intracellular expression and extracellular release of Cat $C$ as well as upregulation of enzymatic activity. On the basis of these results and previous studies showing Cat C mediated peripheral inflammation, we provided cellular evidences to support the notion that Cat $C$ could participate in the development of neuroinflammation in the CNS. Therefore, further studies of the functional role of Cat $\mathrm{C}$ in the mechanism of neuroinflammation in the CNS may provide an insight for the therapeutic prevention and/or treatment of neuroinflammation-involved neurological disorders in the future.

\section{Abbreviations}

BBB: Blood-brain barrier; BCIP: 5-bromo-4-chloro-3-indolyl-phosphate; Cat C: Cathepsin C; CNS: Central nervous system; DIG: Digoxigenin; DPPI: Dipeptidyl peptidase I; DMEM: Dulbecco's modified eagle medium; ELISA: Enzyme-linked immunosorbent assay; FBS: Fetal bovine serum; IHC: Immunohistochemistry; IL: Interleukin; iNOS: Inducible nitrite oxide synthase; ISH: In situ hybridization; kDa: KiloDaltons; LPS: Lipopolysaccharide; mAb: Monoclonal antibody; NBT: 4-nitro blue tetrazolium chloride; NO: Nitrite oxide; PBS: Phosphate buffered saline; RT-PCR: Reverse transcription polymerase chain reaction; SEM: Standard error of the mean; SN: Substantia nigra; TNF-a: Tumor necrosis factor-a.

\section{Competing interests}

The authors declare that they have no competing interests.

\section{Acknowledgements}

This work has been supported by the National Natural Science Foundation of China (Grant Numbers 30771055 and 31050007) to JM, and the Research Fund for the Doctoral Program of Higher Education of China (No. 20102105120001) to KF. We thank Prof. Kazuhiro Ikenaka (National Institute for Physiological Sciences, Japan) for providing the plasmid of Cat C and valuable discussions.

\section{Author details}

'Department of Anatomy, Dalian Medical University, No. 9, West Segment of South Lvshun Road, Dalian, Liaoning 116044, China. ${ }^{2}$ Department of Physiology, Dalian Medical University, No. 9, West Segment of South Lvshun Road, Dalian, Liaoning 116044, China. ${ }^{3}$ Graduate School, Dalian Medical University, No. 9, West Segment of South Lvshun Road, Dalian, Liaoning 116044, China. ${ }^{4}$ General Surgery, Wafangdian Central Hospital, No. 3, Jinluan Road, Wafangdian, Liaoning 116300, China. ${ }^{5}$ Department of Neurology, the First Affiliated Hospital of Dalian Medical University, No. 222, Zhongshan Road, Dalian, Liaoning 116023, China. ${ }^{6}$ Department of Otolaryngology, the First Affiliated Hospital of Dalian Medical University, No. 222, Zhongshan Road, DalianLiaoning, 116023, China.

\section{Authors' contributions}

JM conceived of the study, participated in its design and coordination and helped to draft the manuscript. FK participated in the design of the study, carried out the immunoassays, RT-PCR in vitro and drafted the manuscript. XF carried out enzymatic activity determination in vitro. FB and LN carried out the experiments in vivo. YZ carried out cell culture. YW performed the statistical analysis. All authors read and approved the final manuscript.

\section{Authors' information}

Jianmei Ma, PhD and MD, professor, Department of Anatomy, Dalian Medical University, major in neuroscience, especially in molecular mechanism of demyelinating disease in CNS.

Kai Fan, PhD and MD, associate professor, Department of Anatomy, Dalian Medical University, major in neuroinflammation-involved neurological disorders.
Received: 4 December 2011 Accepted: 20 May 2012

Published: 20 May 2012

\section{References}

1. Glass CK, Saijo K, Winner B, Marchetto MC, Gage FH: Mechanisms underlying inflammation in neurodegeneration. Cell 2010, 140:918-934.

2. Whitton PS: Neuroinflammation and the prospects for anti-inflammatory treatment of Parkinson's disease. Curr Opin Investig Drugs 2010, 11:788-794.

3. Hensley K: Neuroinflammation in Alzheimer's disease: mechanisms, pathologic consequences, and potential for therapeutic manipulation. $J$ Alzheimers Dis 2010, 21:1-14.

4. Herrera AJ, Castano A, Venero JL, Cano J, Machado A: The single intranigral injection of LPS as a new model for studying the selective effects of inflammatory reactions on dopaminergic system. Neurobiol Dis 2000, 7:429-447.

5. Gao HM, Jiang J, Wilson B, Zhang W, Hong JS, Liu B: Microglial activation-mediated delayed and progressive degeneration of rat nigral dopaminergic neurons: relevance to Parkinson's disease. $J$ Neurochem 2002, 81:1285-1297.

6. Wilms H, Zecca L, Rosenstiel P, Sievers J, Deuschl G, Lucius R: Inflammation in Parkinson's diseases and other neurodegenerative diseases: cause and therapeutic implications. Curr Pharm Des 2007, 13:1925-1928.

7. Mogi $\mathrm{M}$, Harada $\mathrm{M}$, Kondo $\mathrm{T}$, Riederer $\mathrm{P}$, Inagaki $\mathrm{H}$, Minami $\mathrm{M}$, Nagatsu $\mathrm{T}$ : Interleukin-1 beta, interleukin-6, epidermal growth factor and transforming growth factor-alpha are elevated in the brain from parkinsonian patients. Neurosci Lett 1994, 180:147-150.

8. Blum-Degen D, Muller T, Kuhn W, Gerlach M, Przuntek H, Riederer P: Interleukin-1 beta and interleukin- 6 are elevated in the cerebrospinal fluid of Alzheimer's and de novo Parkinson's disease patients. Neurosci Lett 1995, 202:17-20

9. Muller T, Blum-Degen D, Przuntek H, Kuhn W: Interleukin-6 levels in cerebrospinal fluid inversely correlate to severity of Parkinson's disease. Acta Neurol Scand 1998, 98:142-144.

10. Knott C, Stern G, Wilkin GP: Inflammatory regulators in Parkinson's disease: iNOS, lipocortin-1, and cyclooxygenases-1 and -2. Mol Cell Neurosci 2000, 16:724-739.

11. Nagatsu T, Sawada M: Inflammatory process in Parkinson's disease: role for cytokines. Curr Pharm Des 2005, 11:999-1016.

12. Whitton PS: Inflammation as a causative factor in the aetiology of Parkinson's disease. Br J Pharmacol 2007, 150:963-976.

13. Eikelenboom P, Zhan SS, Van Gool WA, Allsop D: Inflammatory mechanisms in Alzheimer's disease. Trends Pharmacol Sci 1994 15:447-450.

14. Lee JW, Lee YK, Yuk DY, Choi DY, Ban SB, Oh KW, Hong JT: Neuroinflammation induced by lipopolysaccharide causes cognitive impairment through enhancement of beta-amyloid generation. J Neuroinflamm 2008, 5:37.

15. Petanceska S, Canoll P, Devi AL: Expression of rat cathepsin $\mathrm{S}$ in phagocytic cells. J Biol Chem 1996, 271:4403-4409.

16. Ryan RE, Sloane BF, Sameni M, Wood PL: Microglial cathepsin B: an immunological examination of cellular and secreted species. J Neurochem 1995, 65:1035-1045.

17. Kingham PJ, Pocock JM: Microglial apoptosis induced by chromogranin A is mediated by mitochondrial depolarization and the permeability transition but not by cytochrome c release. J Neurochem 2001, 74: 1452-1462.

18. Nakanishi $H$, Tominaga $K$, Amano T, Hirotsu I, Inoue T, Yamamoto K: Agerelated changes in activities and localizations of cathepsins $D, E, B$, and $L$ in the rat brain tissues. Exp Neurol 1994, 125:1-10.

19. Bernstein HG, Brusziz S, Schmidt D, Wiederanders B, Dorn A: Immunodetection of cathepsin $D$ in neuritic plaques found in brains of patients with dementia of Alzheimer type. J Hirnforsch 1989, 30:613-618.

20. Yoshiyama Y, Arai K, Oli T, Hattori T: Expression of invariant chain and pro-cathepsin L in Alzheimer's brain. Neurosci Lett 2000, 290:125-128.

21. Czapski GA, Gajkowska B, Strosznajder JB: Systemic administration of lipopolysaccharide induces molecular and morphological alterations in the hippocampus. Brain Res 2010, 1356:85-94.

22. Rawlings ND, Morton FR, Barrett AJ: MEROPS: the peptidase database. Nucleic Acids Res 2006, 34:270-272.

23. Deussing J, Kouadio M, Rehman S, Werber I, Schwinde A, Peters C: Identification and characterization of a dense cluster of placenta-specific 
cysteine peptidase genes and related genes on mouse chromosome 13 Genomics 2002, 79:225-240.

24. Turk B, Turk D, Turk V: Lysosomal cysteine proteases: more than scavengers. Biochim Biophys Acta 2000, 1477:98-111.

25. Felbor U, Kessler B, Mothes W, Goebel HH, Ploeggh HL, Bronson RT, Olsen BR: Neuronal loss and brain atrophy in mice lacking cathepsin B and L. Proc Natl Acad Sci USA 2002, 99:7883-7888.

26. Nakanishi $\mathrm{H}$ : Neuronal and microglial cathepsins in aging and age-related diseases. Ageing Res Rev 2003, 2:367-381.

27. Boya P, Kroemer G: Lysosomal membrane permeabilization in cell death. Oncogene 2008, 27:6434-6451.

28. Fei XF, Qin ZH, Xiang B, Li LY, Han F, Fukunaga K, Liang ZQ: Olomoucine inhibits cathepsin L nuclear translocation, activates autophagy and attenuates toxicity of 6-hydroxydopamine. Brain Res 2009, 1264:

85-97.

29. Ma J, Tanaka KF, Yamada G, Ikenaka K: Induced expression of cathepsins and cystatin $C$ in a murine model of demyelination. Neurochem Res 2007, 32:311-320.

30. Paris A, Strukelj B, Pungercar J, Renko M, Dolenc I, Turk V: Molecular cloning and sequence analysis of human preprocathepsin C. FEBS Lett 1995, 369:326-330.

31. Turk D, Janjic V, Stern I, Podobnik M, Lamba D, Dahl SW, Lauritzen C, Pedersen J, Turk V, Turk B: Structure of human dipeptidyl peptidase I (cathepsin C): exclusion domain added to an endopeptidase framework creates the machine for activation of granular serine proteases. EMBO J 2001, 20:6570-6582

32. Rao NV, Rao GV, Hoidal JR: Human dipeptidyl-peptidase I gene characterization, localization, and expression. J Biol Chem 1997, 11: 10260-10265.

33. McGuire MJ, Lipsky PE, Thiele DL: Cloning and characterization of the CDNA encoding mouse dipeptidyl peptidase I (cathepsin C). BBA 1997 1351:267-273.

34. Ishidoh K, Muno D, Sato N, Kominami E: Molecular cloning of cDNA for rat cathepsin C. J Biol Chem 1991, 266:16312-16317.

35. McGuire MJ, Lipsky PE, Thiele DL: Purification and characterization of dipeptidyl peptidase I from human spleen. Arch Biochem Biophys 1992, 295:280-288.

36. Pham CTN, Ley TJ: Dipeptidyl peptidase I is required for the processing and activation of granzymes A and B in vivo. Proc Natl Acad Sci USA 1999, 96:8627-8632.

37. Sheth PD, Pedersen J, Walls AF, McEuen AR: Inhibition of dipeptidyl peptidase I in the human mast cell line HMC-1: blocked activation of tryptase, but not of the predominant chymotryptic activity. Biochem Pharmacol 2003, 66:2251-2262.

38. Adkison AM, Raptis SZ, Kelley DG, Pham CTN: Dipeptidyl peptidase I activates neutrophil-derived serine proteases and regulates the development of acute experimental arthritis. J Clin Invest 2002, 109: 363-371.

39. Hu Y, Pham CT: Dipeptidyl peptidase I regulates the development of collagen-induced arthritis. Athritis Rheum 2005, 52:2553-2558.

40. Clair MJ, Pham CTN, Villalta A, Caughey GH, Wolters PJ: Mast cell dipeptidyl peptidase I mediates survival from sepsis. J Clin Invest 2004, 113:628-634.

41. Bourbeau J, Johnson M: New and controversial therapies for chronic obstructive pulmonary disease. PATS 2009, 6:553-554.

42. Shi GP: Role of cathepsin C in elastase-induced mouse abdominal aortic aneurysms. Future Cardiol 2007, 3:591-593.

43. Akk AM, Simmons PM, Chan HW, Agapov E, Holtzman MJ, Grayson MH, Pham CTN: Dipeptidyl peptidase I-dependent neutrophil recruitment modulates the inflammatory response to Sendai virus infection. J Immunol 2008, 180:3535-3542.

44. Qin LY, Wu XF, Block ML, Liu YX, Breese GR, Hong JS, Knapp DJ, Crews FT: Systemic LPS causes chronic neuroinflammation and progressive neurodegeneration. Glia 2007, 55:453-462.

45. Ma J, Matsumoto M, Tanaka K, Takebayashi H, Ikenaka K: An animal model for late onset chronic demyelinaion disease caused by failed terminal differentiation of oligodendrocyte. Neuron Glia Biol 2006, 2:81-91.

46. Ma J, Tanaka K, Shimizu T: Bernard Claude CA, Kakita A, Takahashi $\mathrm{H}$, Pfeiffer SE, Ikenaka $\mathrm{K}$ : Microglial cystatin $\mathrm{F}$ expression is a sensitive indicator for ongoing demyelination with concurrent remyelination. J Neurosci Res 2011, 89:639-649.
47. Jones E, Adcock IM, Ahmed BY, Punchard NA: Modulation of LPS stimulated NF-KB mediated nitric oxide production by PKC and JAK2 in RAW macrophages. J Inflamm 2007, 4:23.

48. Ward RJ, Wilmet S, Legssyer R, Deroy D, Toussaint L, Crichton RR, Pierreux C, Hue L, Piette J, Srai SK, Solanky N, Klein D, Summer K: Iron supplementation to pregnant rats: effects on pregnancy outcome, iron homeostasis and immune function. Biometals 2009, 22:211-223.

49. Perry $\mathrm{VH}$ : The influence of systemic inflammation on inflammation in the brain: implications for chronic neurodegenerative disease. Brain Behav Immun 2004, 18:407-413.

50. Sparkman NL, Martin LA, Calvert WS, Boehm GW: Effects of intraperitoneal lipopolysaccharide on Morris maze performance in year-old and 2month-old female C57BL/6J mice. Behav Brain Res 2005, 159:145-151.

51. Shaw KN, Commins S, O'Mara SM: Lipopolysaccharide causes deficits in spatial learning in the water maze but not in BDNF expression in the rat dentate gyrus. Behav Brain Res 2001, 124:47-54.

52. Fink MP, Fiallo V, Stein KL, Gardiner WM: Systemic and regional hemodynamic changes after intraperitoneal endotoxin in rabbits: development of a new model of the clinical syndrome of hyperdynamic sepsis. Circ Shock 1987, 22:73-81.

53. Opal SM: The host response to endotoxin, antilipopolysaccharide strategies, and the management of severe sepsis. Int J Med Microbiol 2007, 297:365-377

54. Beishuizen A, Thijs LG: Endotoxin and the hypothalamo-pituitary-adrenal (HPA) axis. J Endotox Res 2003, 9:3-24

55. Gabellec MM, Griffais R, Fillion G, Haour F: Expression of interleukin 1 alpha, interleukin 1 beta and interleukin 1 receptor antagonist mRNA in mouse brain: regulation by bacterial lipopolysaccharide (LPS) treatment. Brain Res Mol Brain Res 1995, 31:122-130.

56. Hansen MK, Nguyen KT, Goehler LE, Gaykema RP, Fleshner M, Maier SF, Watkins LR: Effects of vagotomy on lipopolysaccharide-induced brain interleukin-1beta protein in rats. Auton Neurosci 2000, 85:119-126.

57. Turrin NP, Gayle D, Ilyin SE, Flynn MC, Langhans W, Schwartz GJ, PlataSalaman CR: Pro-inflammatory and anti-inflammatory cytokine mRNA induction in the periphery and brain following intraperitoneal administration of bacterial lipopolysaccharide. Brain Res Bull 2001, 54: $443-453$.

58. Jann B, Reske K, Jann K: Heterogeneity of lipopolysaccharides. Analysis of polysaccharide chain lengths by sodium dodecylsulfate-polyacrylamide gel electrophoresis. Eur J Biochem 1975, 60:239-246.

59. Banks WA, Robinson SM: Minimal penetration of lipopolysaccharide across the murine blood-brain barrier. Brain Behav Immun 2010, 24: 102-109.

60. Laflamme N, Rivest S: Toll-like receptor 4: the missing link of the cerebral innate immune response triggered by circulating gram-negative bacterial cell wall components. FASEB J 2001, 15:155-163.

61. Thibeault I, Laflamme N, Rivest S: Regulation of the gene encoding the monocyte chemoattractant protein (MCP-1) in the mouse and rat brain in response to circulating LPS and proinflammatory cytokines. J Comp Neurol 2001, 434:461-477.

62. Tomás-Camardiel M, Rite I, Herrera AJ, de Pablos RM, Cano J, Machado A Venero $J$ : Minocycline reduces the lipopolysaccharide-induced inflammatory reaction, peroxynitrite-mediated nitration of proteins, disruption of the blood-brain barrier, and damage in the nigral dopaminergic system. Neurobiol Dis 2004, 16:190-201.

63. Ji KA, Yang MS, Jeong HK, Min KJ, Kang SH, Jou I, Joe EH: Resident microglia die and infiltrated neutrophils and monocytes become major inflammatory cells in lipopolysaccharide-injected brain. Glia 2007, 55:1577-1588

64. Jeong HK, Jou I, Joe EH: Systemic LPS administration induces brain inflammation but not dopaminergic neuronal death in the substantia nigra. Exp Mol Med 2010, 12:823-832.

65. Hart PS, Zhang Y, Firatli E, Uygur C, Lotfazar M, Michalec MD, Marks JJ, Lu X, Coates B: Identification of cathepsin $C$ mutations in ethnically diverse Papillon-Lefèvre syndrome patients. J Med Genet 2001, 37:927-932.

66. Xi G, Reiser G, Keep RF: The role of thrombin and thrombin receptors in ischemic, hemorrhagic and traumatic brain injury: deleterious or protective? J Neurochem 2003, 84:3-9

67. Striggow F, Riek M, Breder J, Henrich-Noack P, Reymann KG, Reiser G: The protease thrombin is an endogenous mediator of hippocampal neuroprotection against ischemia at low concentrations but causes 
degeneration at high concentrations. Proc Natl Acad Sci USA 2000, 97:2264-2269.

68. Sawada K, Nishibori M, Nakaya N, Wang Z, Saeki K: Purification and characterization of a trypsin-like serine proteinase from rat brain slices that degrades laminin and type IV collagen and stimulates protease-activated receptor-2. J Neurochem 2000, 74:1731-1738

69. Perry VH, Gordon S: Macrophages and the nervous system. Int Rev Cytol $1991,125: 203-244$

70. Nathan CF: Secretory products of macrophages. J Clin Invest 1987, 79: 319-326.

71. Giulian D, Corpuz M: Microglial secretion products and their impact on the nervous system. Adv Neurol 1993, 59:315-320.

72. Dahl SW, Halkier T, Lauritzen C, Dolenc I, Pedersen J, Turk V, Turk B: Human recombinant pro-dipeptidyl peptidase I (cathepsin C) can be activated by cathepsin $\mathrm{L}$ and $\mathrm{S}$ but not by autocatalytic processing. Biochemistry 2001, 40:1671-1678.

doi:10.1186/1742-2094-9-96

Cite this article as: Fan et al:: Up-regulation of microglial cathepsin C expression and activity in lipopolysaccharide-induced

neuroinflammation. Journal of Neuroinflammation 2012 9:96.

\section{Submit your next manuscript to BioMed Central and take full advantage of:}

- Convenient online submission

- Thorough peer review

- No space constraints or color figure charges

- Immediate publication on acceptance

- Inclusion in PubMed, CAS, Scopus and Google Scholar

- Research which is freely available for redistribution 